\title{
Study on Woolen Clothing and Pattern Unearthed in Zagunluk Cemetery in Qiemo County of Xinjiang
}

\author{
Xiaojuan Mao ${ }^{1}$ \\ ${ }^{1}$ Fashion and Design College, Donghua University, Shanghai, China \\ ${ }^{2}$ College of Textile and Clothing, Xinjiang University, Urumqi, Xinjiang, China \\ Correspondence: Xiaojuan Mao. E-mail: maoxj916@163.com
}

$\begin{aligned} & \text { Received: February 16, } 2018 \quad \text { Accepted: March 26, } 2018 \quad \text { Online Published: April 19, } 2018 \\ & \text { doi:10.5539/ass.v14n5p95 }\end{aligned}$ URL: https://doi.org/10.5539/ass.v14n5p95

\begin{abstract}
Located in the western border of the motherland, Xinjiang Uyghur Autonomous Region used to be the hub of the ancient Silk Road. Known as Western Regions, it has created splendid multi-ethnic cultures with distinctive geographical features. With its multiple archeological resources, there are many exquisite historic relics unearthed here, which shocked the world, with woolen fabrics as the most characteristic and the earliest fabrics. Zagunluk Cemetery witnessed sufficient unearthed fabrics in quantities and types. This paper focuses on woolen clothing and accessories and their patterns unearthed in Zagunluk Cemetery, Qiemo County, Xinjiang Uyghur Autonomous Region. Zagunluke woolen clothing and accessories reflect the circumstances of evolving weaving technologies in ancient Xinjiang. These woolen clothing and accessories were daily necessities of ancestors of Zagunluk, witnessing their material and cultural life. This paper analyzes about 20 typical woolen clothes and accessories, attempting to find out the characteristics of woolen fabric patterns and their formation background.
\end{abstract}

Keywords: Zagunluk cemetery, woolen fabric, woolen clothing, woolen patterns

\section{Introduction}

Zagunluk Cemetery is Located in Gobi Desert at the west of Zagunluk Village, $5 \mathrm{~km}$ away from Qiemo County in the southwest. It is so named because it is close to Zagunluk Village.

The Cemetery are divided into two areas of south and north; there are many tombs in the south and the tombs there are more concentrated; there are relatively less toms in the north and are more scattered. A total of 167 tombs have been excavated; a lot of wool fabrics were unearthed, dating from the 8th century BC to the 2 nd century BC.

By searching for information of woolen fabric unearthed in Zagunluk Cemetery, the author has sorted out 20 pieces of woolen clothing, which may be dated from about 2800 years ago and in the same period with Zhou Dynasty. Production processes of woolen clothing unearthed in Zagunluk Cemetery are also abundant; besides weaving, there are printing and dyeing. There are different styles of woolen patterns precisely because of these different production processes. The main use of these woolen fabrics are for clothing, including uppers, skirts, trousers, hats, socks, scarves, etc.

\section{Woolen Clothing}

\subsection{Clothing}

There are many kinds of woolen woven garments unearthed in Zagunluk Cemetery .The style of clothing may be thick, loosely fitting, heavy robes; light, thin, porous woolen gauze clothing; and woven skirt of various colors that are joined together. The woolen clothes that appear in this article are more complete, the style is also very clear.

\subsubsection{Uppers}

Basic styles of uppers unearthed in Zagunluk Cemetery: mainly cardigan and pullover, cardigan prevails. The following are a few uppers in good conditions.

Brown woolen cloth robe (85QZM2:10). The length is $145 \mathrm{~cm}$, the width is about $110-220 \mathrm{~cm}$. The structure of the woolen fabric is twill weave; lower hem and neckline have purplish red weaved cording trim; front and cuff 
are decorated with cording (Figure 1).

White short-sleeveed woolen cloth jacket with brown stripes (85QZM2:10). The length is $80 \mathrm{~cm}$ long, the width is $86 \mathrm{~cm}$. The sleeves are $31 \mathrm{~cm}$ long and $17.5 \mathrm{~cm}$ wide. The style is straight cut and left and right front openings, small round collar, narrow short sleeves and short garment length; entirely relaxed, made of woolen cloth with original white brown vertical stripes, bright overall color of the woolen cloth, with a certain degree of gloss effect viewed at a distance (Figure 2).

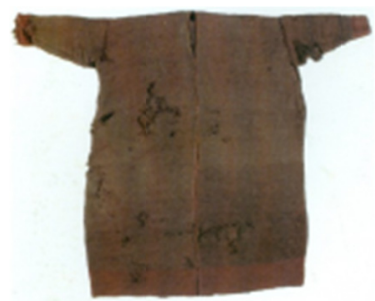

Figure 1. Brown woolen cloth robe (85QZM2:10)

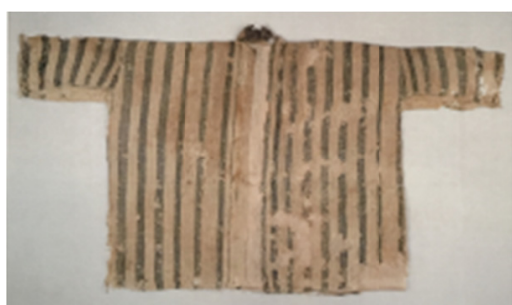

Figure 2. White short-sleeveed woolen cloth jacket with brown stripes (85QZM4:26)

Crimson cardigan gown residual (85QZM2:34). The length is $126 \mathrm{~cm}$; the width is $86 \mathrm{~cm}$. The length of the sleeves are $32 \mathrm{~cm}$; the width are $20 \mathrm{~cm}$; cuffs are $15 \mathrm{~cm}$ wide. This outerwear is seriously incomplete, but overall clothing is bright-colored (Figure 3).

Children's felt one-piece dress (96QZIM55:17G). The length is $63 \mathrm{~cm}$ and the width of the hemline of the dress is $65 \mathrm{~cm}$; upper part of the dress is a joint of woolen cloth with red, white and brown square geometric patterns; sleeves are made of full red coarse woolen cloth. The lower part is made of brown coarse woolen cloth. This style has very modern clothing features (Figure 4).

Woolen cloth pullover jacket, with brown stripes on a white ground (96QZIM14:75C). The length is $79 \mathrm{~cm}$, and the width is $63 \mathrm{~cm}$. The sleeves are $37.5 \mathrm{~cm}$ long; cuffs are $14 \mathrm{~cm}$ wide. The neck opening is $21.5 \mathrm{~cm}$ wide; the deep of the neckline is $5 \mathrm{~cm}$. There is more damage on the lower left side of the garment. This pullover jacket is made of two kinds of woolen fabric (Figure 5).

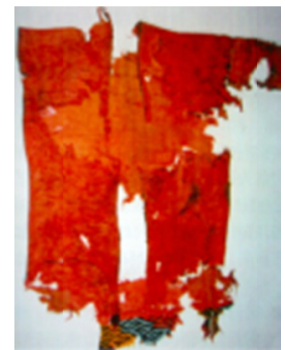

Figure 3. Crimson cardigan gown residual (85QZM2:34)

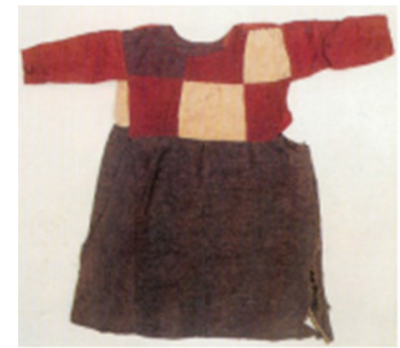

Figure 4. Children's felt one-piece dress (96QZIM55:17G)

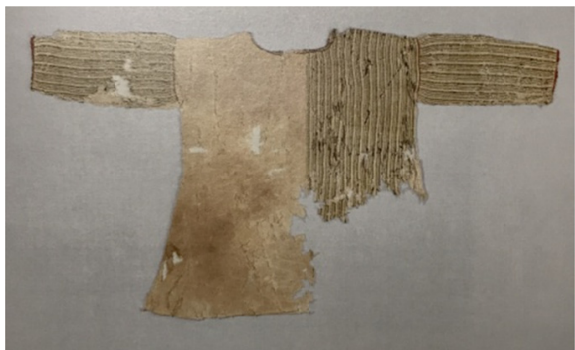

Figure 5. Woolen cloth pullover jacket, with brown stripes on a white ground (96QZIM14:75C)

\subsubsection{Bottoms}

Bottoms sorted mainly include trousers and skirts; few trousers are in complete conditions.

Blue woolen cloth trousers with tapestry designs (85QZM4:50) are $124 \mathrm{~cm}$ long and $105 \mathrm{~cm}$ wide and straight cut. Trouser legs and crotch are respectively woven, and then stitched together with the rest of the trousers. Cuff has color pattern. Style of trousers is as shown in Figure 6.

Dark brown woolen cloth trousers, $136 \mathrm{~cm}$ long and $62 \mathrm{~cm}$ wide. The bottom of trousers is $31 \mathrm{~cm}$ wide. The style is high-waisted straight-leg pants. The bottom hem of the trousers is weaved with a red trim $4 \mathrm{~cm}$ wide. In this way can increase the aesthetic feeling, as shown in Figure 7.

Woolen-cloth trousers (98QZIM141:1), brown ground with Qianzhi (Brocading).length of the trousers is $119 \mathrm{~cm}$, width at the waist is $75 \mathrm{~cm}$. The cuffs is $23 \mathrm{~cm}$ wide. The trousers are narrow in the leg. The woolen cloth is extremely fine and soft. The broken line patterns of the trousers is on the thigh. And both front and back carry 
this pattern. The broken line patterns is 3 for a group, longitudinal arrangement, and made up of five colors white, red, yellow, blue and green (Figure 8).

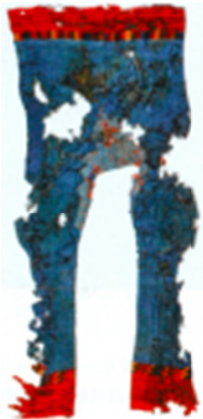

Figure 6. Blue woolen cloth trousers (85QZM4:50)

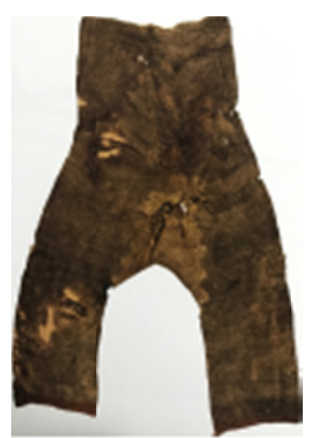

Figure 7. Blue woolen cloth trousers

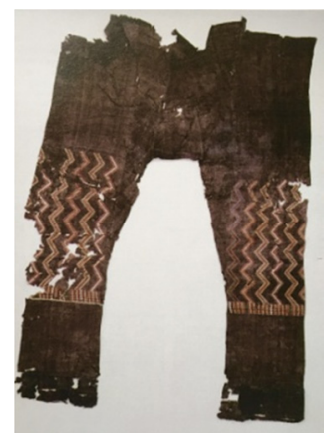

Figure 8. Woolen-cloth trousers (98QZIM141:1)

Colored skirt made of woolen braids (85QZM2:38), $28 \mathrm{~cm}$ long and 92 $\mathrm{cm}$ wide; red, orange and green plaided or water rippled woven straps stitched horizontally. These woolen ribbons are woven into a neat and elegant woven skirt, as shown in Figure 9.

White tubular skirt with tapestry-woven (98QZIM136:13D), the length of the skirt is $100 \mathrm{~cm}$, the width at the waist is $81 \mathrm{~cm}$, and the width at lower hem is $82 \mathrm{~cm}$. The straight tubular skirt is composed of three pieces of woolen cloth put together lengthwise. The tapestry-woven pattern on the skirt is a horizontal strip, $1.2 \mathrm{~cm}$ wide. This pattern is triangular geometry, with red, dark red, azure, military green, yellow, tan, white and blue eight colors alternately formed (Figure 10).

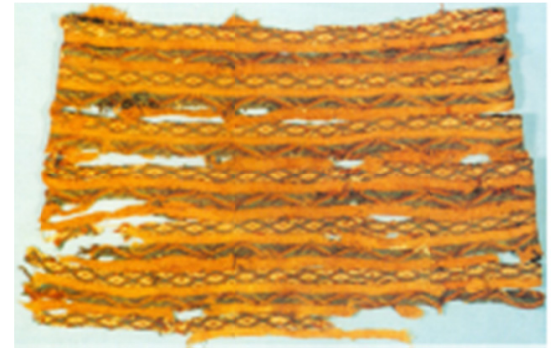

Figure 9. Colored skirt made of woolen braids (85QZM2:38)

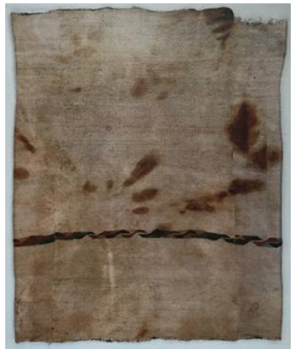

Figure 10. Colored skirt made of woolen braids (85QZM2:38)

The woolen knitted garments unearthed in Zagunluke have formed a simple and concise style on the basis of practicality. The diversity of these woolen clothing category shows that people are actively pursuing life. So we can see that the strong local cultural characteristics from these woolen clothing.

\subsection{Woolen Garment Accessories}

The woolen garment accessories unearthed in Zagunluke cemetery are exquisite and rich in variety. They also have a variety of decorative styles. Some of these accessories are practical and some are decorative. The following are a few more representative woolen garment accessories.

Yellow ground twill weave woolen shawl (85QZM4:80), $149 \mathrm{~cm}$ long, $60 \mathrm{~cm}$ wide. It is in rectangular shape; both ends of the shawl have twist tassels that run through both ends; tassels are about $20 \mathrm{~cm}$ long. Shawl has been kept relatively complete; the hand-painted wave swirling patterns are exquisite (Figure 11).

Felt chest- protector (96QZIM65:18-1D), $46 \mathrm{~cm}$ long, $38 \mathrm{~cm}$ wide. It was sewed of plain-weave coarse cotton cloth. There are fixed strips on round collar. Drab background is decorated with dark blue fine strips. As shown in figure. 


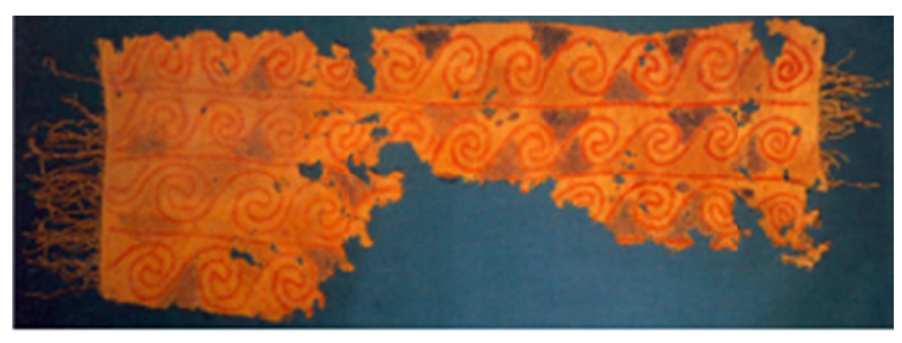

Figure 11. Yellow ground twill weave woolen shawl (85QZM4:80)

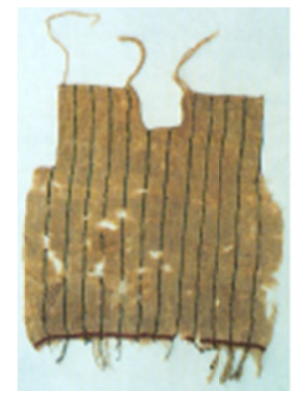

Figure 12. Felt chest- protector (96QZIM65:18-1D)

Brown wool-knitted cap, $7.5 \mathrm{~cm}$ long, diameter $18 \mathrm{~cm}$. The outside is a brown knitted mesh hood filled with coarse wool. Appearance of this cap is similar to modern beret, as shown in Figure 13.

Dark brown felt cap with pointed top, $32.7 \mathrm{~cm}$ high, diameter $24 \mathrm{~cm}$. The cap is made of white thick line with whipstitch. The cap with steel top is also favorite type of nomads. It has not only strong practicality but also very decorative effect, as shown in Figure 14.

Woolen handbag in tapestry-weave (98QZIM147:26). The body of the handbag is $16.3 \mathrm{~cm}$ long and $15 \mathrm{~cm}$ wide. The tassels is $8 \mathrm{~cm}$ long. The carrying strap is $19 \mathrm{~cm}$ long. The handbag is rectangular and made up of the bag body, a rope handle, and tassels. There are the five colors red, yellow, green, white and purple on a blue ground. The pattern on the handbag is very special. As shown in Figure1 5.

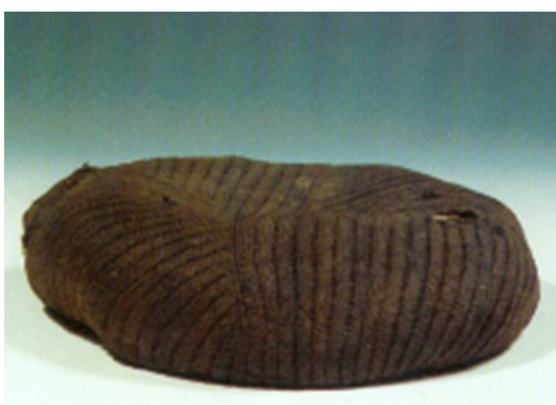

Figure 13. Brown wool-knitted cap

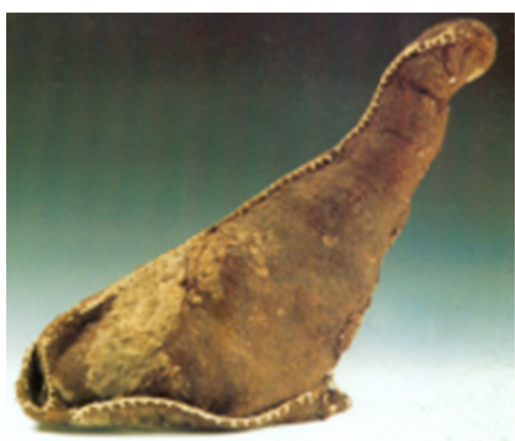

Figure 14. Dark brown felt cap with pointed top

Woolen bag with striped pattern in various colors (98QZIM149:2), $67 \mathrm{~cm}$ long and $16.5 \mathrm{~cm}$ wide. This bag is rectangular and was made of one piece of woolen cloth, folded crosswise and sewn. It has seven colors: white, blue, yellow, brown, green, red and light red. When this woolen bag was excavated, there were preserved traces of wheaten food inside the bag. As we can see, the woolen bag is used for food, as shown in Figure 16.

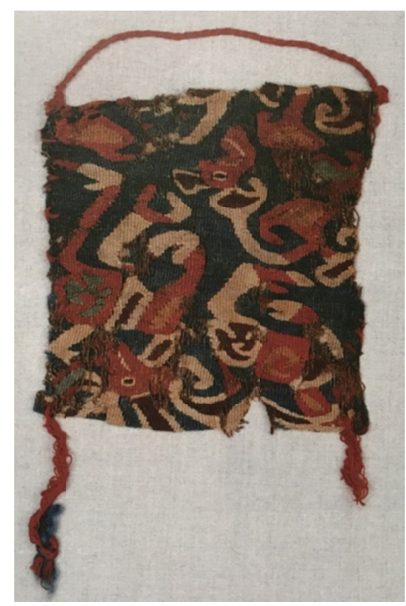

Figure 15. Woolen handbag in tapestry-weave (98QZIM147:26)

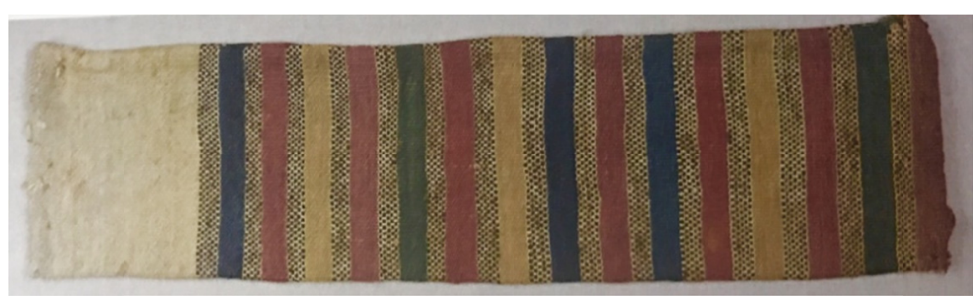

Figure 16. Woolen bag with striped pattern in various colors (98QZIM149:2) 


\section{Fabric Types of Woolen Clothing}

Woolen fabric unearthed in Zagunluk Cemetery is rich in variety and adopts various weaving techniques, which fully demonstrates yearning of ancestors for good life and the expression. Here is description of fabric mainly adopts the Woolen fabric "He", Ke weave method, embedded weaving and colored woven straps, etc.

\subsection{The Woolen Fabric "He"}

In fact, "He" is a kind of ancient woolen fabric. This Woolen fabric unearthed in Zagunluk Cemetery is mainly divided into twill weave and plain types. Among them the tabby woolen fabric is mostly.

(1) Twill weave

There are 29 pieces of twill weave unearthed in Zagunluk Cemetery. They are sewn into uppers, trousers, stockings, etc. Some shawls are also made of twill fabric. These unearthed twill textiles are divided into twill original texture and double-sided reinforcement twill texture.

(2) Tabby

Woolen fabric of plain weave is also common in Zagunluk Cemetery, where there are about over 40 pieces. The woven fabric structure is also divided into original weave and plain joint weave. Woolen fabric of such plain weave is thin and light and usually used to sew uppers, trousers or shawl, cover sheet, etc. used in spring and winter and feels comfortable.

\subsection{The Woolen Fabric of Ke Weave Method}

There are 8 pieces of woolen fabric in tapestry-weave unearthed in Zagunluk Cemetery; this very unique weaving method is called that the warp passes through and returns as the weft. This technology first appeared in the Mediterranean region and the same as the reeling process in Tang Dynasty. The woven patterns are usually decorated in lower hem of uppers, hemline of skirt or waist and bottom of trousers. As shown in Figure17.

\subsection{The Woolen Fabric of Inlaying Weaves and Jacquards Embedded}

2 pieces of (Brocading) woolen fabric unearthed in Zagunluk Cemetery, both of which have patterns woven on plain weave so that it has more prominent decorative effect (Figure 18).

\subsection{The Woolen Fabric of Colored Woven Strips}

Embellished joint skirt made of colored woven strip is one of the most distinctive wool fabrics in Zagunluk Cemetery. Woolen yarns of a variety of colors are used to weave colored woven strips that are sewn together to become a beautiful dress (Figure 9).

\subsection{Embroidery}

A lot of embroidery was unearthed in Zagunluk Cemetery. The techniques included flat stitch, chain stitch and composite technique. The method of the embroidery is mainly to show rich patterns on the woolen fabric, which can serve as a good decorative effect (Figure 19).

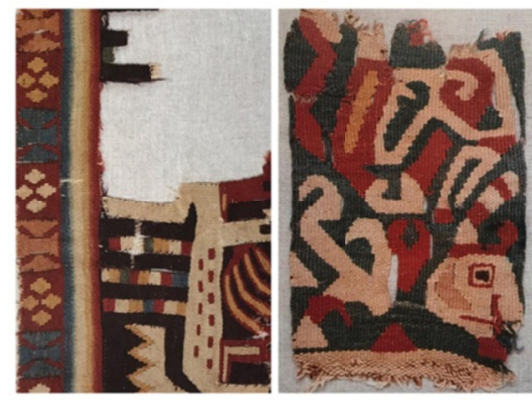

Figure 17. Woolen fabric in tapestry-weave

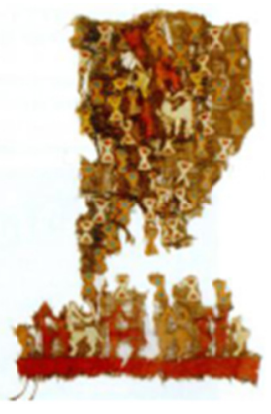

Figure 18. The woolen fabric of inlaying weaves and jacquards Embedded

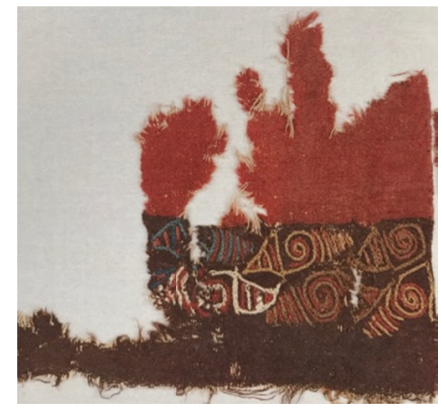

Figure 19. Embroidery

\section{Woolen Patterns}

Woolen fabric unearthed in Zagunluk Cemetery is rich in variety; patterns are varied and mainly geometric patterns and animal pattern. Some of these patterns are complete and some are incomplete. They are mainly present in the unearthed woolen clothing and fragments of the woolen fabric. 


\subsection{Geometric Patterns}

Geometric pattern is common for woolen fabric unearthed in Zagunluk Cemetery and bright in color. There are mainly diamond patterns, zigzag patterns, hook patterns, hook thunder patterns, vortex patterns, plaid, basket, etc. mainly decorated at lower hem of coat, waist of trousers and bottom of trousers, as Table 1 .

Table 1. The types of geometric patterns of unearthed woolen fabric in Zagunluk cemetery

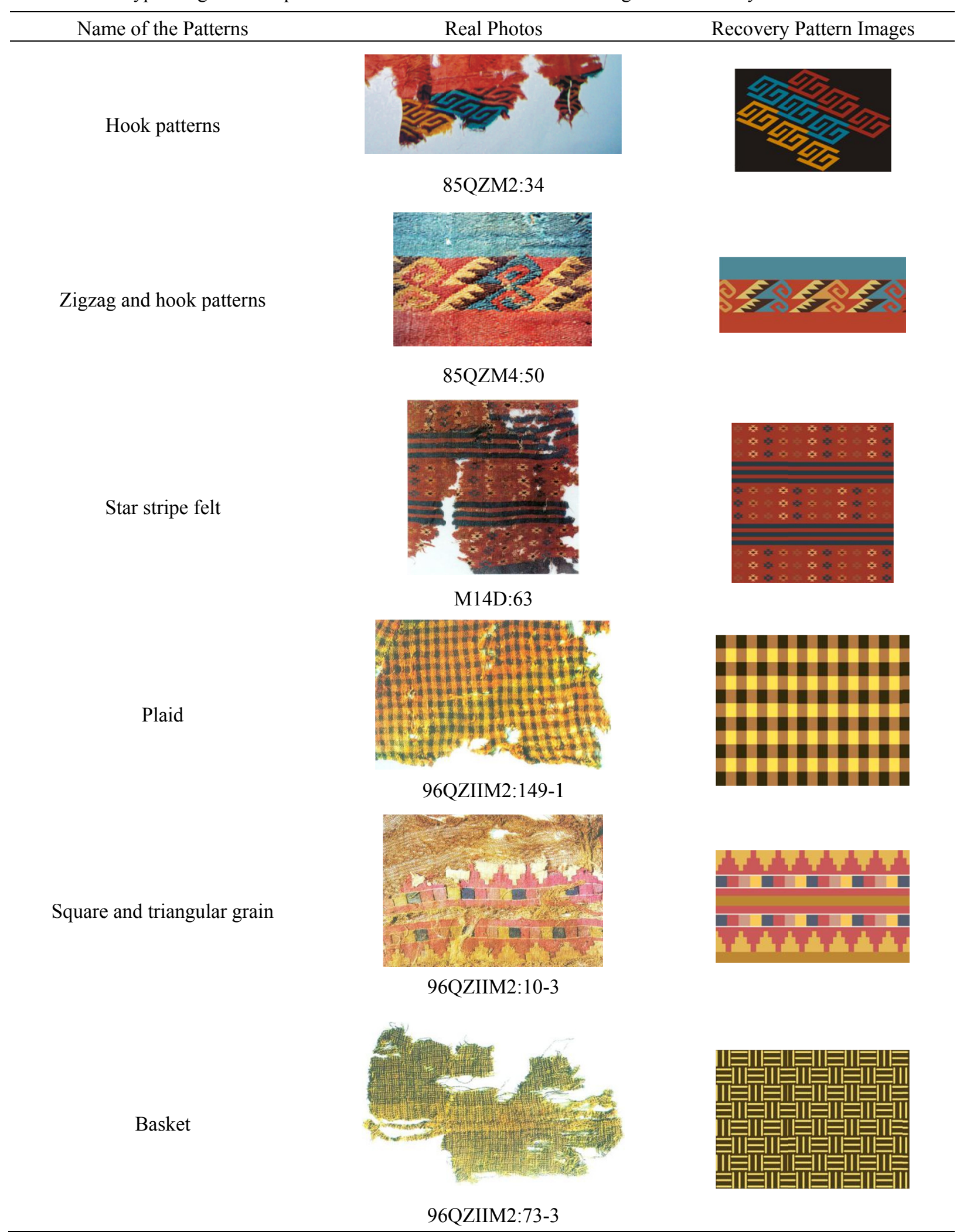


Vortex pattern
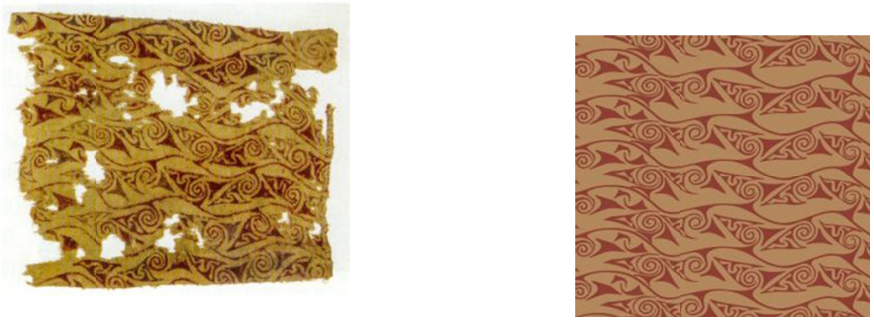

85QZM4:79

Note. the recovery patterns of the article are drawn by the author.

These geometric patterns not only appear on the woolen fabric, but also appear on other articles for daily use, such as the wood spindles with carved designs. Its diameter of the bottom is about $5 \mathrm{~cm}$ and its thickness is about $3 \mathrm{~cm}$. The spindle is about $14 \mathrm{~cm}$ long and its diameter is about $0.9 \mathrm{~cm}$. Its made of poplar. The botton of the spindle looks like half of a ball. There is a vortex pattern carved on it. This kind of vortex pattern is similar to yellow ground oblique woolen shawl.

\subsection{Animal patterns}

Animal patterns of woolen fabric unearthed in Zagunluk Cemetery are like sheep, pigs, fish, dragons and other shapes, most of which are made by embedded weaving, woof weaving and hand drawing. Embedded waving technique is typically demonstrated in antelope-pattern woolen cloth unearthed at 1985 No.3 cemetery in Phase II of Zagunluk, which is $81 \mathrm{~cm}$ long and $41 \mathrm{~cm}$ wide, with reddish brown background and patterns of red, blue and light yellow embedded weaving antelope and touching triangle patterns. As shown in Figure 20.

The residual woolen tapestry with animal patterns. The lenth of the residual woolen tapestry is $26.3 \mathrm{~cm}$, while the width is $13 \mathrm{~cm}$, pattern bottom made of red and green alternated herring-bone wide stripes, each stripe with pattern of variant animal looking like jumping sheep or deer that turns round and overlook; colorful and vivid patterns, Figure 21.

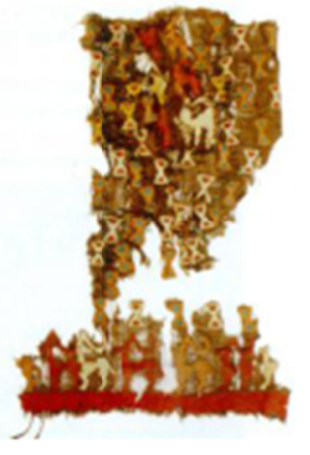

Figure 20. Brown ground embedded woolen shawl (85QZM3:10)

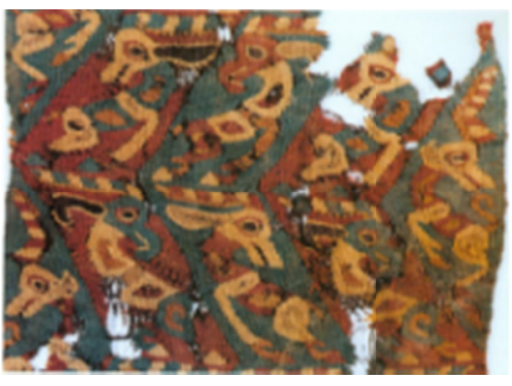

Figure 21. Tapestry-woven blue woolen band with animal patterns (96QZIM34:50)

Hand-painted woolen fabric pattern is a unique pattern expression form in Zagunluk cemetery. The main patterns are drawn in red on light yellow or original white plain weave or twill wool fabric or partially embellished with black or green to play a more prominent decorative effect. Only one of these hand-painted woolen fabrics unearthed includes hand-painted pattern on original white fabric; the others are all first woven and then dyed (light yellow prevails) and finally hand-painted.

Patterns are varied, focusing on animal patterns, such as wild dragons pattern, camels pattern, tigers pattern, and deformed fish pattern. The following are analysis of three characteristic hand-painted woolen fabric animal patterns. Figure 22 shows yellow ground with tigers patterns woolen fabric sock remnant (85QZM4:56), consisting of yellow woolen fabric ground, tiger outline drawn with red lines with its ears and legs drawn with red spiral patterns, tail drooping and tail tip coiling, mouth and claws dotted with brown points. The current fabric pattern remnant consists of 3 horizontal rows and 9 vertical rows, showing the tiger is walking, and the two adjacent rows showing walking in the opposite directions. Painting lines are fluid, making tiger image 
realistic and attractive. The woolen fabric has several irregular red points, deductive ink dots left by hand-painted patterns.

Figure 23 shows white ground with camels and wild boars patterns crawlers remnant (85QZM4: 23-2), length: $76 \mathrm{~cm}$, width: $34 \mathrm{~cm}$, consisting of white ground, red wild boar and camel patterns, remaining 4 animals in horizontal rows and 4 longitudinal rows, each row witnessing 4 consistent walking camel and wild boar patterns, and the 2 adjacent rows showing walking in the opposite directions. Each camel pattern length: $10 \mathrm{~cm}$, width: $12 \mathrm{~cm}$, wild boar pattern length: $7 \mathrm{~cm}$, width: $10 \mathrm{~cm}$. Wild boar drawn with red lines, with big head, round eyes, sharp mouth and drooping tail. Its plump buttocks are drawn with spiral patterns, with horizontal blotch patterns on the back and yellow spots and lines dotted on the back and 2 hooves. Camels are also painted with red lines, witnessing double hump and short tail, the neck below the head drawn as an arc, buttocks drawn with spiral patterns. Camels were important means of transport and pack in the desert oasis, closely related to the local people, and naturally favored by them. People used to describe them on woolen fabrics and carved them on wooden barrels, making them traditional decorative patterns.

Figure 24 shows yellow ground painted variant fish woolen fabric skirt remnant (85QZM4: 23-1), remaining length: $115 \mathrm{~cm}$, width: $56 \mathrm{~cm}$, witnessing a rectangle, consisting of yellow ground, fish outline drawn with red lines, some colorless, and some dark purple. The part shown in the picture holds 2 full breadths, painted with 4 rows of fish patterns. The middle 2 rows show relative fish belly and opposite fish head. The fish arranged on the upper and lower sides show relative fish back and opposite fish head. Fish patterns slightly deformed, with big head like open mouth, curved fish body and tail, fish belly with downward continuous semicircular fish scale patterns. These fish patterns vary in size, maximum length: $14 \mathrm{~cm}$, width: $8 \mathrm{~cm}$, minimum length: $11 \mathrm{~cm}$, width: $6 \mathrm{~cm}$. The fish patterns prove rivers adjacent to residences, and consequent fish pattern on woolen clothing.

Although the strokes are poorly executed and the shapes irregular, showing that the artist's skil was deficient and that they were rather lackadaisical about the way the design was painted. But it is a beautiful expression of the nomadic life. And this method has been used in modern times.

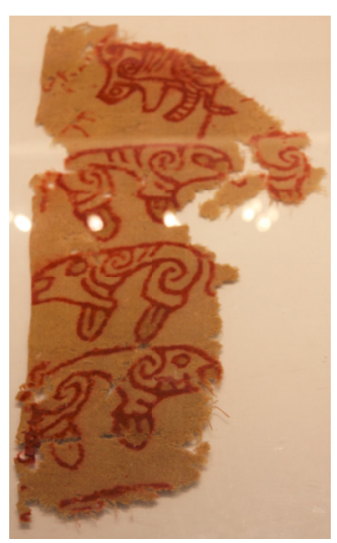

Figure 22. Tigers patterns woolen fabric (85QZM4:56)

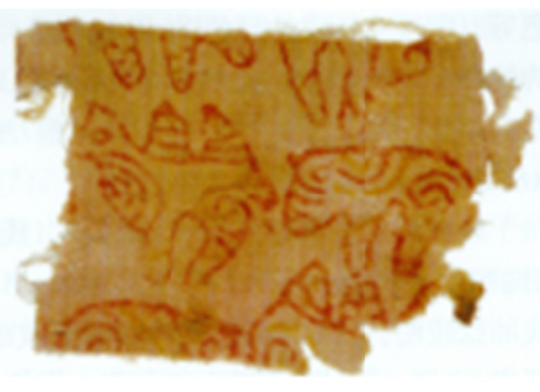

Figure 23. Camels and wild boars patterns crawlers remnant (85QZM4: 23-2)

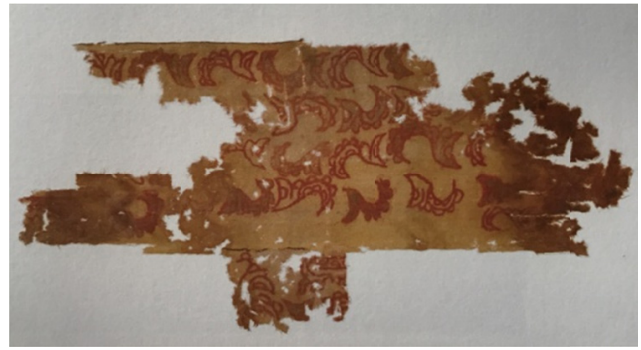

Figure 24. variant fish woolen fabric skirt remnant (85QZM4: 23-1)

Animal patterns have been favored by grassland residents, widely distributed in the Eurasian steppe. Woolen fabric patterns unearthed in Zagunluk Cemetery were multiple animals including sheep, antelope, camel, wild boar and deer, staying vertical, semi-vertical, reverse and horizontal. Reverse animal patterns have been found in other cemeteries in Xinjiang grassland, such as Sampula and Alagou. Mr. Jia Yingyi proposed that the woolen fabrics with animal patterns first appeared in Zagunluk Cemetery, Qiemo, Xinjiang, namely the remnants of the 3 pieces of hand-painted woolen fabrics mentioned above, indicating ancestors of Zagunluk were skilled in woolen fabric production and decoration.

\section{Conclusions}

1. The pre-historic economy of Zagunluke was dominated by animal husbandry, with horses, cattles, sheep, deer, amels, donkeys, etc. The handicraft industry include wood carving, weaving, leather making and so on. The woolen textiles have an important place in the region. From the unearthed woolen fabric clothing can be seen very distinct nomadic culture. 
2. Woolen clothing unearthed in Zagunluk Cemetery of different styles and varieties. These fabrics well reflect people's wisdom at that time and high-level textile skills.

3. Patterns of woolen fabrics are various; the patterns show aesthetic pursuit of people in daily life. These show that their rich regional and ethnic features and the diversity and creativity of its ancient culture. Because the woolen fabric unearthed is seriously incomplete, it has a large impact on further study of composition and arrangement mode of woolen fabric.

\section{References}

Aliya. (1998). Studay on Hand-painted Patterns of Woolen Fabric Unearthed in Zagunluk Cemetery in Charchan County of Xinjiang in 1985. Cultural relics of Xinjiang.

Binghua, W. (2002). The Ancient Corpses of Xinjiang, China. Urumqi: Xinjiang People Publishing House.

Bo, W., \& Mingfang, W. (2009, September). Research on the Wool Textile Unearther from Zhagunluke Cemetery. Urumqi. Journal of Xinjiang Normal University (Social Sciences), 30(3), 77-85.

Bo, W., \& Mingfang, W. (2010). The Wool Embroidery Unearther from Zagunluke Cemetery. Relics and Museology, 3.

Shunying, M. (1994). The Ancient Art in Xinjiang. Urumqi: Xinjiang Art Photography Publishing House.

Xiaojuan, M. (2014). Study on Geometric Pattern of Unearthed Woolen Fabric from Xinjiang. Advances in Textile Engineering and Materials IV, Advanced Materials Research, 1048, 318-321.

Xinjiang Institute of Archaeology, Xinjiang Uygur Autonomous Region Museum. (1999). A Grand View of Xinjiang's Cultural Relics and Historic Sites. Urumqi: Xinjiang Art Photography Publishing House.

Yingyi, J. (2015). Studies on the Woolen Textile in Ancient Xinjiang. Shanghai: Shanghai Classics Publishing House.

\section{Copyrights}

Copyright for this article is retained by the author(s), with first publication rights granted to the journal.

This is an open-access article distributed under the terms and conditions of the Creative Commons Attribution license (http://creativecommons.org/licenses/by/4.0/). 